\title{
Recovery and discovery
}

\author{
The recent disappearance of a commercial airliner has highlighted our poor knowledge of the ocean \\ floor. Through the years, human tragedies have helped inspire deep sea research, but it is time to explore \\ more systematically.
}

On 8 March 2014, a commercial airliner carrying 239 people disappeared almost without a trace. The path of flight MH370, which fell off military radar a few hours after take-off, was painstakingly reconstructed from a few bits of data gleaned from a telecommunications satellite. The analysis suggested the plane made an abrupt turn away from its original destination of Beijing, instead heading south over the Indian Ocean. Guided by the satellite data and sightings of possible airplane debris, search teams narrowed in on an area of the Indian Ocean west of the Australian coast. But as the teams began their - ultimately fruitless - search of this patch of the ocean floor, they hit a snag: the topography of the sea floor in this region was virtually unknown. This piece of uncharted territory is not exceptional: broad swathes of the ocean floor are yet to be fully explored.

Mapping of the sea floor is not just an exercise in disaster recovery. Much of the ocean's internal mixing is attributed to rough topography at the sea floor; this sort of mixing is a key way in which wind and tidal energy is dissipated throughout the ocean (Nikurashin, M. Vallis, G. K. \& Adcroft, A. Nature Geosci. 6, 48-51; 2013). Poor knowledge of how energy is transformed in the world's oceans hinders forecasts of everything from the path of tsunamis to the ocean's uptake of heat and carbon dioxide (Smith, W. H. F. \& Marks, K. M. Eos 95, 173-174; 2014).

For the Indian Ocean floor off the coast of western Australia, progress is being made. In late May, a map using satellite data to fill in the blanks between the sparse bathymetric surveys of this region was released (Smith, W. H. F. \& Marks, K. M. Eos 95, 173-174; 2014). And as the search area expanded to a zone of around $60,000 \mathrm{~km}^{2}$, the Australian government initiated an exercise to map the sea floor at a far higher resolution than can be obtained from satellites.

The Australian government has indicated the data will be made publicly available to aid future scientific studies. Yet, even the relatively coarse satellite seafloor map released in May shows dramatic

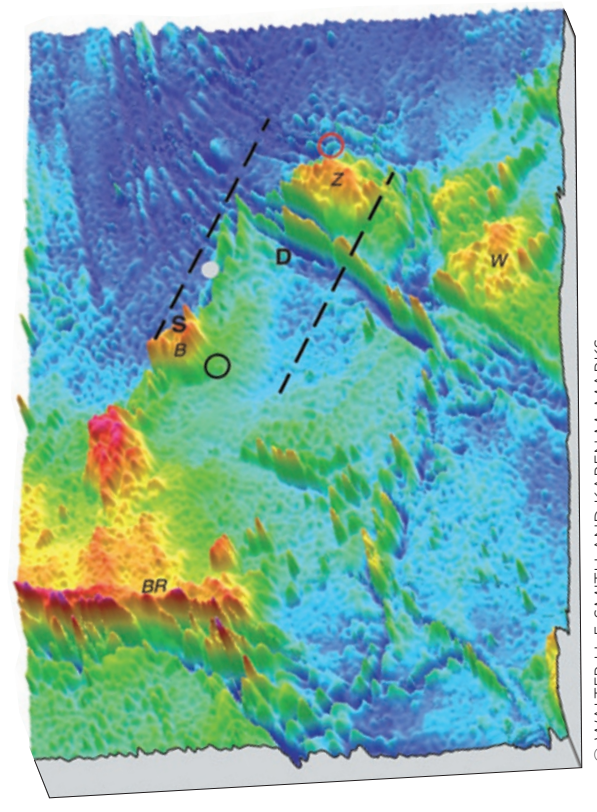

eventually piloted the submersible to the deepest known point on Earth. During test dives to over $8,000 \mathrm{~m}$ in the New Britain trench, Cameron encountered the deepest pillow lavas found to date; these features formed as lava was extruded under the high pressures of the ocean. In the Sirena Deep, he and expedition scientists found microbial mats growing around an area thought to host serpentinization. Analyses of these mats could provide insights into both the chemical processing and the life that evolved to take advantage of it. The Deepsea Challenger was later donated to the Woods Hole Oceanographic Institution.

In the western Pacific, the rugged terrain of Nikumaroro Atoll may hide the remains of Amelia Earhart's Electra 10E aircraft, suggests the International Group for Historical Aircraft Recovery (www.tighar.org). Earhart and her navigator disappeared along with their plane in 1937, while trying to land on Howland Island. They were nearly threequarters of the way into an attempt to fly around the world. The atoll is considered one of the most pristine coral reefs in existence, based on SCUBA surveys. Seafloor mapping of the western edge of the atoll by TIGHAR shows the steep, rugged topography of the deeper coral reef.

A funding appeal for an undersea search of the atoll's western flank, scheduled to take place in the autumn of 2014, is currently underway (http://go.nature.com/ nZJ8am), with a plan for two submersibles to search for evidence of wreckage and to carry out a survey of the deep reef. It is hoped that the assessment will provide a baseline for reef diversity and health.

Just as rewards such as mineral deposits and hotspots of biodiversity lurk beneath the ocean's surface, so do hazards. Yet the ocean's floor is less well-charted than the surface of Mars or the Moon. Clearly, a blanket of a few thousand metres of sea water is a serious obstacle to exploration. But if we can reach these depths when disaster strikes, technology is clearly not the barrier to mapping the ocean floor. We just need to set our minds (and funds) to the task. 